Çukurova Üniversitesi Mühendislik Mimarlık Fakültesi Dergisi, 32(4), ss. 11-20, Aralık 2017

Çukurova University Journal of the Faculty of Engineering and Architecture, 32(4), pp. 11-20, December 2017

\title{
Çanakkale Tuzla Jeotermal Sondaj Sahası Çamur Maliyetinin Araştırılması
}

\author{
Yasin ERDOĞAN ${ }^{* 1}$, Onur Eser KÖK ${ }^{\mathbf{1}}$, Ilknur TANRIVERDİ ${ }^{\mathbf{1}}$ \\ ${ }^{1}$ İskenderun Teknik Üniversitesi, Mühendislik ve Doğa Bilimleri Fakültesi, Petrol ve Doğal Gaz \\ Mühendisliği Bölümü, HATAY
}

Geliş tarihi: 01.07.2017

Kabul tarihi: 19.12.2017

\section{Özet}

Son yıllarda jeotermal enerji kullanım alanları hızla artmaktadır. Bu durum jeotermal enerjiye olan talebi ve böylece jeotermal sondajlarına yapılan yatırımları artırmıştır. Sondaj faaliyetlerinde kritik noktaların başında maliyet faktörü yer alır. Sondaj maliyetinin önemli kısmını çamur maliyeti oluşturmaktır. Dolayısı ile fizibilite çalışmalarında sondaj çamuru için birim maliyet hesabı toplam maliyetin hesaplanmasında büyük rol oynamaktadır.

Bu çalışmada Çanakkale, Tuzla bölgesi, Çamköy formasyonunda yapılan $2542 \mathrm{~m}$ derinliğindeki bir jeotermal kaynak sondajı incelenmiştir. Yapılan sondaja spud çamuru ile başlanmış olup sonrasında sırasıyla lignosülfonat ve polimer çamuru ile devam edilmiştir. Çamur maliyetleri her bir kuyu çapı için ve her çamur türü için ayrı ayrı hesaplanmış ve birim maliyet olarak incelenmiştir. Yapılan hesaplamalar sonucu tüm kademelerde kullanılan ve sondajın bitimine kadar kullanılan toplam çamur katkı malzemesi maliyeti 53464,43 \$ olarak hesaplanmıştır. Varil birim maliyeti, 5,92 \$, metre birim maliyeti ise 24,43 \$ olarak hesaplanmışıtır.

Anahtar Kelimeler: Sondaj çamuru, Bentonit, Spud çamuru, Lignosülfonat çamuru, Maliyet

\section{Investigation of Mud Cost for Geothermal Drilling Field in Çanakkale Tuzla Region}

\begin{abstract}
In recent years geothermal energy use areas are increasing rapidly. This has increased the demand for geothermal energy and thus the investments in geothermal drilling. The cost factor is the first of the critical points in drilling activities. Much of the drilling cost is to make mud cost. Therefore, the unit cost for drilling mud in feasibility studies plays a major role in calculating the total cost.

In this study, a geothermal drilling at $2542 \mathrm{~m}$ depth in Çanakkale, Tuzla region, Çamköy formation was investigated. Drilling was started with spud mud. Then lignosulfonate mud was used afterwards. Lastly polymer mud was used. Drilling mud costs were calculated separately for each well diameter and for each type of mud and were examined as unit cost. The total cost of the drilling mud additive used in all stages of calculations and used up to the end of the drilling was calculated as 53464,43\$. Barrel unit cost was calculated as $5,92 \$$ and meter unit cost was calculated as $24,43 \$$.
\end{abstract}

Keywords: Drilling mud, Bentonite, Spud mud, Lignosulfonate mud, Cost

"Corresponding author (Sorumlu yazar): Yasin ERDOĞAN, yasin.erdogan@iste.edu.tr 


\section{GİRIŞ}

Bir jeotermal kaynak sondajının maliyetini danışmanlık hizmetleri, çamur maliyetleri, malzeme alımı, lokasyon hazırlıkları, lojistik, malzeme kirası, çimento maliyeti, yapılan jeolojik çalışmalar ve kuyu testleri, personel giderleri (maaş, konaklama, yemek vb.) ve sondaj sigortası gibi sabit giderler, tahlisiye operasyonları, mekanik arıza giderleri, ekstra malzeme alımı veya ekstra kuyu testleri gibi değişkenlik gösteren parametreler oluşturmaktadır. $\mathrm{Bu}$ parametreler arasında toplam maliyeti en çok etkileyenlerden birisi de çamur maliyetleridir [1].

Çamur maliyetleri, bir sondajda toplam maliyeti hem doğrudan hem de diğer parametreler üzerinde değişkenlik sağladığı için dolaylı olarak etkilemektedir. Bu yüzden fizibilite çalışmalarında hem toplam çamur maliyeti hem de birim maliyeti göz önünde bulundurulmaktadır. Bir sondaj maliyetinin ortalama \%15-20 kadarını çamur maliyetleri ve dolaylı olarak etkilediği maliyetler oluşturmaktadır. Ayrıca çamur sirkülasyon esnasında derinlik ve jeotermal kaynaktan meydana gelen sıcaklık artışının etkisi ile maliyet açısından değişkenlik oluşmaktadır.

Kuyu tabanındaki çamurun sıcaklığı $50-70{ }^{\circ} \mathrm{C}$ aralığında olduğu durumlarda çamur maliyetinin yaklaşık olarak \%70 oranında arttığ $1,70{ }^{\circ} \mathrm{C}$ 'den fazla olduğu durumlarda ise \%133 oranında bir maliyet artışının meydana geldiği belirtilmiştir. $\mathrm{Bu}$ durum ise jeotermal sondajlarda sıcaklığın çamur üzerindeki etkisinden kaynaklı maliyet artışını göstermektedir. Dolayısı ile petrol ya da doğalgaz sondajlarına göre jeotermal sondajların çamur maliyetlerinin daha fazla olduğu görülmektedir [2].

Yapılan bu çalışmada, Çanakkale Tuzla Bölgesi Çamköy Formasyonu içerisinde yapılan bir jeotermal kaynak sondajı incelenmiştir. Sondaj $2542 \mathrm{~m}$ derinlikte $26^{1 / 2}$ inç, 22 inç, $17^{1 / 2}$ inç, $12^{1 / 4}$ inç ve $8^{1 / 2}$ inç kademeleri ile tamamlanmıştır. 0-266 m arasinda Spud, 266-1550 $\mathrm{m}$ arasinda
Lignosülfonat, 1550-2188 m arasında ise Polimer çamur sistemi ile devam edilmiştir.

Devamında ise su ile sondaj tamamlanmıştır. Kullanılan çamur sistemlerinde hazırlanan çamur miktarı ve kullanılan katkı malzemeleri sondajın yapıldığ 1 tarih olan Ocak/2015 dönemi fiyatları ile verilmiştir. Hesaplamalar sonucunda her kademe için çamur maliyeti ile birlikte metre başına maliyet hesaplanmıştır. Ayrıca, sondajın toplam çamur maliyeti hesaplanmış ve metre başına birim çamur maliyeti belirlenmiştir. Hesaplamalar sirasinda para birimi olarak dolar kuru kullanılmıştır.

\section{2. ÇALIŞMA ALANI}

Sondaj lokasyonu Çanakkale İli Çamköy formasyonu içerisinde yer almaktadır. Sondajın yapıldığı saha konum olarak Kuzeybatı Anadolu'da Biga yarımadasının batı kesiminde Kuzeybatı Anadolu genç volkanizmasının yaygın olarak izlendiği bir bölgededir. Ayvalık I 16- $\mathrm{d}_{2}$ paftası ile I 16-d paftasının büyük bir kısmını ve yaklaşık $250 \mathrm{~km}^{2}$ 'lik bir alanı kapsamaktadır. Bu alan, coğrafik olarak Kazdağ yükseliminin güneybatı kesimlerinde Ege Denize uzanan engebeli ve düzlük alanlar ile temsil edilmektedir. Bu bölgede Paleozoyik, Mesozoyik ve Senozoyik yaşlı kayaçların yer aldığı görülmektedir [3].

Bölgede stratigrafik istifin temelinde, Ezine Zonu içerisinde değerlendirilen Karadağ Grubu kayaçları yer almaktadır. Mostra vermeyen birim, genel olarak mermer ve çeşitli şistlerden oluşmaktadır. Kambriyen-Triyas yaşlı kayaçlardan oluşan Karadağ Grubu, çalışma sahasının kuzeyinde; Kösedere, Tavaklı ve Geyikli civarında yayılım göstermektedir [4].

Çalışma alanının genelleştirilmiş stratigrafik kesiti (ölçeksiz) Şekil 1'de verilmiştir. Ayrıca Şekil 2'de Tuzla jeotermal sahasının 1/25.000 ölçekli jeoloji haritası bulunmaktadır. 


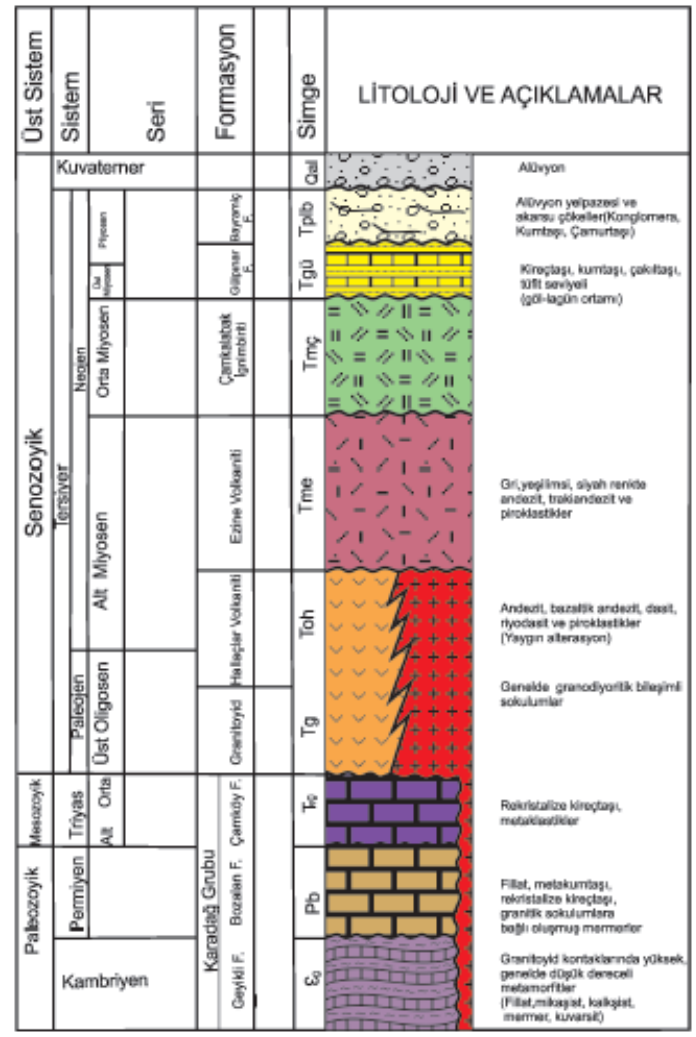

Şekil 1. Çalı̧̧ma alanının genelleştirilmiş stratigrafik kesiti (ölçeksiz) [5]

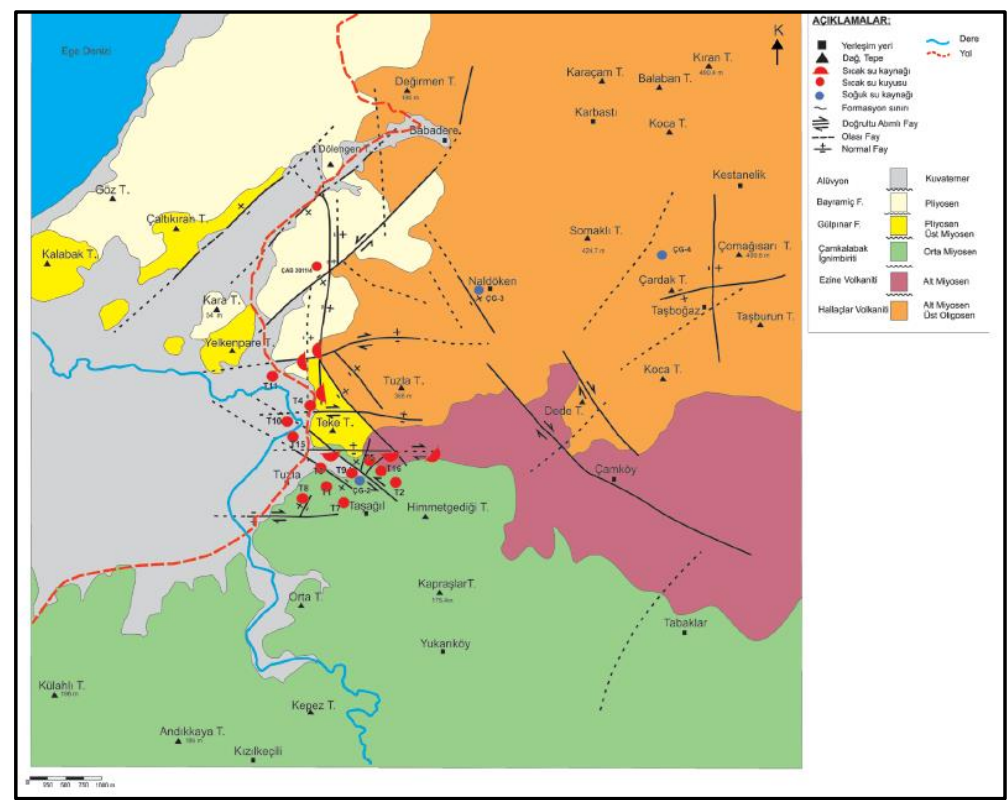

Şekil 2. Tuzla jeotermal sahasının 1/25.000 ölçekli jeoloji haritası [5] 
Sondaj alanının yerbulduru haritası ve lokasyon planı Şekil 3 ve 4'de verilmiştir.

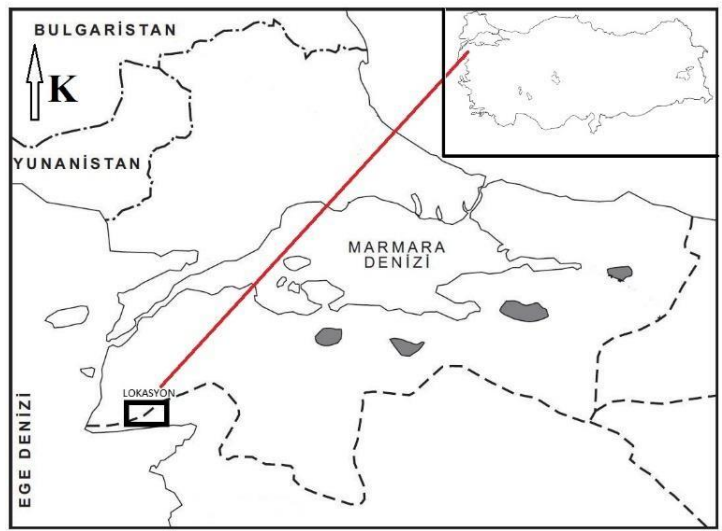

Şekil 3. Sondaj alanı yer bulduru haritası

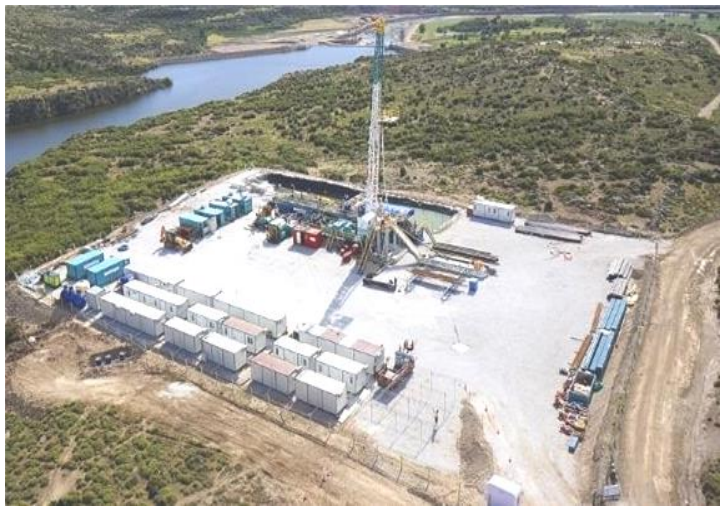

Şekil 4. Sondaj alanı lokasyon plan görünümü

\section{KULLANILAN ÇAMUR TÜRLERI VE KATKI MALZEMELERİ}

Sondaj çamur türleri derinlik ve formasyona göre değişiklik göstermektedir. Genellikle başlangıçta spud tip, devamında lignosülfonat tip ve rezervuar derinliğe ulaşıldığında polimer tip sondaj çamuru kullanılmaktadır.

Sondaj çamuru türüne ve formasyon ile etkileşimine bağlı olarak kullanılacak katkı malzemeleri de değişiklik göstermektedir. Genel olarak bentonit, soda külü $\left(\mathrm{Na}_{2} \mathrm{CO}_{3}\right)$, kostik soda $(\mathrm{NaOH})$, kromsuz lignosülfonat (CFL), düşük viskozite sağlayan karboksimetil selüloz (CMC-
LV), yüksek viskozite sağlayan karboksimetil selüloz (CMC-HV), düşük viskozite sağlayan polianyonik selüloz (PAC-LV), xanthan sakızı (XCD), sitrik asit $\left(\mathrm{C}_{6} \mathrm{H}_{8} \mathrm{O}_{7}\right)$, barit $\left(\mathrm{BaSO}_{4}\right)$ ve kalsiyum karbonat $\left(\mathrm{CaCO}_{3}\right)$ kullanılmaktadır. Katk1 malzemelerinin kullanım amaçları farklılık göstermektedir (Çizelge 1).

\subsection{Spud Çamuru}

Genel olarak sondaj operasyonunun ilk metrajlarında, kuyu çapının en büyük olduğu aralığın delinmesi sırasında kullanılan çamur türüdür. Su bazlı çamur türlerinden olup reaktif çamurlardan biridir. Spud çamurlarının temel katkı maddesi bentonittir (API Spec 13A veya TSE ISO EN 13500 nolu standartlarına uygun). Su sertliğini azaltmak amacı ile soda külü, pH kontrolü için ise kostik soda kullanılmaktadır. Ayrıca, formasyona bağlı olarak CMC-HV ve CMC-LV kullanılmaktadır [6,7].

Spud çamuru hazırlanması kolay olduğu için sıklıkla tercih edilir. Uygun reolojik özellikler ve iyi hidrolik planlama ile geniş kuyu anülüsünde biriken tanecik boyutu büyük kesintilerin temizlenerek yüzeye getirilmesini sağlar.

\subsection{Lignosülfonat Çamuru}

Sondaj derinliğinin artması ile birlikte kullanılmaya başlanılan tatlı su kaynaklı bir reaktif çamur türüdür. Kompozisyon içerisinde bentonit, CFL, kostik soda, soda külü, CMC-HV, CMC-LV ve sitrik asit kullanılmaktadır. [7,8]. Kuyu dibi sıcaklığının yükseldiği durumda sıvı kaybı ve viskozite kontrolü için PAC-LV, sedimanların yüzeye taşınmasını kolaylaştırmak için XCD, hidrostatik basıncı artırmak için barit ve $\mathrm{CaCO}_{3}$ kullanılmaktadır.

Katk1 malzemeleri arasında önemli olan CFL, çamurun viskoz özelliklerinin artmasını ve flokülasyonu engeller. Bu yüzden $\mathrm{CFL}$ delinen formasyonlardan gelen katı maddelerin ve kimyasal kirlenmelerin olumsuz etkilerinden korumak için kullanılır. Lignosülfanat çamurunun hazırlanması ve bakımı sondaj uygulamaları bakımından oldukça kolay ve ucuz olarak 
kullanılan bir çamur tipidir. Yaygın olarak kullanılan bu çamur türü çok özel bir sondaj problemleri yaşanmadığı sürece başarıyla kullanılmaktadır [8].

\subsection{Polimer Çamuru}

Rezervuar kayaca ulaşıldığında ya da delinirken kullanılan, olası kaçak ve çamur problemlerini en aza indirecek şekilde hazırlanan çamura polimer çamuru denilmektedir. Bu çamur özellikle kaçak riski içeren formasyonlarda oluşabilecek çamur kayıplarını minimize etmek için kullanılır. $\mathrm{Bu}$ nedenle kaçak önleyiciler içerir ve sediman taşıma kapasitesi yüksektir.

Kompozisyon içerisinde XCD, kostik soda, PAC-LV, $\mathrm{CaCO}_{3}$ ve sitrik asit kullanılmaktadır. Oluşabilecek kaçak hacimlerinin doldurulması ya da kapatılabilmesi için çamurun çok hızlı bir şekilde hazırlanabilmesi gerekmektedir. Hedef seviyelerde asit operasyonları yapılabileceği göz önünde bulundurularak kompozisyonda yer alan bütün katkı maddelerinin $\mathrm{HCl}$ asitte çözünür olmasına dikkat edilmelidir [9].

Çizelge 1. Sondajlarda kullanılan başlıca kimyasal türleri [10]

\begin{tabular}{|c|c|c|}
\hline KATKI MADDESİ & FORMÜL & AÇIKLAMA \\
\hline Bentonit & - & $\begin{array}{l}\text { API Spec 13A Section } 9 \text { standardına uygun, yüksek } \\
\text { şişme kapasitesine sahip kil mineralidir. }\end{array}$ \\
\hline Kostik Soda & $\mathrm{NaOH}$ & $\begin{array}{l}\text { Yüksek saflıktaki sodyum hidroksittir. Ph dengelemek } \\
\text { için kullanılır. }\end{array}$ \\
\hline Soda Külü & $\mathrm{Na}_{2} \mathrm{CO}_{3}$ & $\begin{array}{l}\text { Çamurun flokülesinde veya Ph artmasında, ortamdaki } \\
\mathrm{Ca}^{+2} \text { iyonlarının çöktürülmesini sağlar. Su bazlı çamur } \\
\text { sistemlerinde kullanılır. }\end{array}$ \\
\hline $\begin{array}{l}\text { Yüksek Viskoziteli } \\
\text { Karboksimetil Selüloz } \\
\text { (CMC }- \text { HV })\end{array}$ & $\mathrm{CH}_{2} \mathrm{CO}_{2} \mathrm{H}$ & $\begin{array}{l}\text { Su kaybı düşürücü bir çamur katkısıdır. Yüksek } \\
\text { viskozite artışı sağlar. Sıcaklığa dayanımı düşüktür. }\end{array}$ \\
\hline $\begin{array}{c}\text { Düşük Viskoziteli } \\
\text { Karboksimetil Selüloz } \\
(\mathrm{CMC}-\mathrm{LV}) \\
\end{array}$ & $\mathrm{C}_{6} \mathrm{H}_{9} \mathrm{OCH}_{2} \mathrm{COONa}$ & $\begin{array}{l}\text { Su kaybı düşürücü bir çamur katkısıdır. Düşük viskozite } \\
\text { artışı sağlar. Sıcaklığa dayanımı düşüktür. }\end{array}$ \\
\hline $\begin{array}{c}\text { Düşük Viskoziteli } \\
\text { Polianyonik Selüloz (PAC } \\
- \text { LV) }\end{array}$ & $\begin{array}{l}\mathrm{C}_{6} \mathrm{H}_{7} \mathrm{O}_{2}(\mathrm{OH})_{2} \mathrm{OCH}_{2} \\
\mathrm{COONa}\end{array}$ & $\begin{array}{l}\text { Modifiye edilmiş yüksek kalite polianyonik selülozdur. } \\
\text { Özellikle düşük viskozite artışı sağlayarak su kaybı } \\
\text { kontrolünde kullanılır. }\end{array}$ \\
\hline $\begin{array}{l}\text { Kromsuz Lignosülfonat } \\
\text { (CFL) }\end{array}$ & - & $\begin{array}{l}\text { Asıl olarak deflokülant (dağıtıcı) olarak kullanılır. Etkili } \\
\text { bir şekilde viskoziteyi azaltır. Tüm su bazlı sondaj } \\
\text { çamurlarında sıvı kaybını da kısmi olarak azaltır. } \\
\text { Sıcaklığa dayanımı } 130{ }^{\circ} C^{\circ} \text { 'tır. }\end{array}$ \\
\hline Xsantam Sakızı (XCD) & $\mathrm{C}_{35} \mathrm{H}_{49} \mathrm{O}_{29}$ & $\begin{array}{l}\text { Çamur içerisinde kolay dağılabilen bir katkı maddesidir. } \\
\text { Deniz suları ve tatlı sularda viskozite artırmak ve çamur } \\
\text { içerisindeki katı maddelerin süspansiyonunu sağlamak } \\
\text { için kullanılır. YP/PV oranını artırır. }\end{array}$ \\
\hline Barit & $\mathrm{BaSO}_{4}$ & $\begin{array}{l}\text { Çamurun ağırlığını artırmak için en fazla kullanılan } \\
\text { katkı maddesidir. Özgül ağırlığı } 4,2-4,35 \text { aralığında } \\
\text { değişmektedir. }\end{array}$ \\
\hline Sitrik Asit & $\mathrm{C}_{6} \mathrm{H}_{8} \mathrm{O}_{7}$ & $\begin{array}{l}\text { Organik asit olup su bazlı sondaj sıvılarında Ph değerini } \\
\text { düşürmek ve çözünebilir haldeki kalsiyum ile demir } \\
\text { iyonlarını etkisiz hale getirmek amacıyla kullanılır. }\end{array}$ \\
\hline Kalsiyum Karbonat & $\mathrm{CaCO}_{3}$ & $\begin{array}{l}\text { Polimer çamurunun ağırlığını artırmak için kullanılan } \\
\text { katkı maddesidir. }\end{array}$ \\
\hline
\end{tabular}




\section{ARAŞTIRMA VE BULGULAR}

Kuyu çapına göre her sondaj kademesi için kullanılan çamur katkı malzemeleri bu kısımda belirtilmiştir. Ayrıca toplam çamur maliyeti, birim varil maliyeti, metre başı çamur maliyeti ve kuyu çap1 kademelerinin toplam çamur maliyetine etki oranları hesaplanmıştır. Yapılan sondaj da 2188. metre'den sonra sondaj çamur türü olarak su kullanıldığı için maliyeti hesaplanmamıştır. Hesaplamalarda sondajın yapıldığı dönem olan Ocak/2015 fiyatları kullanılmıştır.

\section{1. $26^{1 / 2}$ inç Kuyu Çapı Kademesi}

Çamköy formasyonunda yapılan sondaj operasyonu $26^{1 / 2}$ inç kuyu çapı ile başlamıştır. Kademe boyunca çamur türü olarak $300 \mathrm{BBL}$ hacminde hazırlanan spud tipi çamur kullanılmıştır. Çamurun hazırlanmasında ve sirkülasyon esnasında reolojik özelliklerin korunabilmesi için sıvı kaybı azaltıcı ve viskozite artırıcı katkı malzemesi olarak bentonit ve CMC-HV, sertlik kontrolü için Soda Külü kullanılmıştır.

$\mathrm{Bu}$ kademede Flow-Line sicaklığ $\breve{1}_{1}$ en yüksek $38,8{ }^{\circ} \mathrm{C}$ değerine ulaşmıştır. Ayrıca casing ve bakım onarım süreleri dahil olacak şekilde ilerleme oranı (Rate of Penetration-ROP) 4,71 metre/gün olarak hesaplanmıştır.

Kullanılan çamur katkı malzemelerinin ambalaj türü, tüketim miktarı ile birim varil ve toplam kademe maliyeti Çizelge 2'de verilmiştir.

Çizelge 2. $26^{1 / 2}$ inç kuyu çapı için maliyet analizi

\begin{tabular}{|c|c|c|c|c|}
\hline Malzeme & Ambalaj & $\begin{array}{c}\text { Birim } \\
\text { Maliyet } \\
\mathbf{( \$ )}\end{array}$ & $\begin{array}{c}\text { Toplam } \\
\text { Kullanim } \\
\text { (Adet) }\end{array}$ & $\begin{array}{c}\text { Toplam } \\
\text { Maliyet } \\
\mathbf{( \$ )}\end{array}$ \\
\hline Bentonit & $\begin{array}{c}35 \mathrm{~kg} / \\
\text { torba }\end{array}$ & 5,65 & 30 & 169,5 \\
\hline Bentonit & $\begin{array}{c}1 \mathrm{ton} / \\
\text { BigBag }\end{array}$ & 161,70 & 1 & 161,70 \\
\hline Soda Külü & $\begin{array}{c}25 \mathrm{~kg} \\
/ \text { torba }\end{array}$ & 9,57 & 1 & 9,57 \\
\hline CMC-HV & $\begin{array}{c}25 \mathrm{~kg} / \\
\text { torba }\end{array}$ & 50,53 & 3 & 151,59 \\
\hline \multicolumn{5}{|c|}{ Toplam Kademe Maliyeti (\$) } \\
\hline \multicolumn{5}{|c|}{ Birim Varil Maliyeti (\$/Bbl) } \\
\hline
\end{tabular}

$26^{1 / 2}$ inç kuyu çapı kademesinde kullanılan çamur katkı malzemeleri için toplam maliyet 492,36 \$, hazırlanan yeni çamur için ise birim varil maliyeti 1,64 \$ olarak hesaplanmıştır.

\subsection{2 inç Kuyu Çapı Kademesi}

$\mathrm{Bu}$ kademeye geçilmeden önce 24 inç koruma borusu (Casing) indirilip çimentolanmıştır. Kademe boyunca çamur türü olarak 920 BBL hacminde hazırlanan Lignosülfonat tip çamur kullanılmıştır. Çamurun hazırlanmasında ve sirkülasyon esnasında reolojik özelliklerin korunabilmesi için sıvı kaybı azaltıcı ve viskozite artırıcı katkı malzemesi olarak Bentonit, CMC-HV ve CMC-LV, sertlik kontrolü için Soda Külü, $\mathrm{pH}$ kontrolü için Sitrik Asit ve Kostik Soda, deflokülant katkı malzemesi olarak CFL kullanılmıştır.

Bu kademede Flow-Line sicaklığı en yüksek $45,4{ }^{\circ} \mathrm{C}$ değerine ulaşmıştır. Ayrıca casing ve bakım onarım süreleri dahil olacak şekilde ROP 16,64 metre/gün olarak hesaplanmıştır.

Kullanılan çamur katkı malzemelerinin ambalaj türü, tüketim miktarı ile birim varil ve toplam kademe maliyeti Çizelge 3'de verilmiştir.

Çizelge 3. 22 inç kuyu çapı için maliyet analizi

\begin{tabular}{|c|c|c|c|c|}
\hline Malzeme & Ambalaj & $\underset{\text { Maliyet }}{\text { Birim }}$ & $\begin{array}{c}\text { Toplam } \\
\text { Kullanım } \\
\text { (Adet) }\end{array}$ & $\begin{array}{c}\text { Toplam } \\
\text { Maliyet } \\
\text { (\$) }\end{array}$ \\
\hline Bentonit & $\begin{array}{c}35 \mathrm{~kg} / \\
\text { torba }\end{array}$ & 5,65 & 45 & 254,2 \\
\hline Bentonit & $\begin{array}{c}1 \mathrm{ton} / \\
\text { BigBag }\end{array}$ & 161,70 & 5 & 808,5 \\
\hline $\begin{array}{l}\text { Soda } \\
\text { Külü }\end{array}$ & $\begin{array}{l}25 \mathrm{~kg} / \\
\text { torba }\end{array}$ & 9,57 & 7 & 66,9 \\
\hline $\begin{array}{l}\text { Kostik } \\
\text { Soda }\end{array}$ & $\begin{array}{c}25 \mathrm{~kg} / \\
\text { torba }\end{array}$ & 23,94 & 6 & 143,6 \\
\hline CMC-HV & $\begin{array}{c}25 \mathrm{~kg} / \\
\text { torba }\end{array}$ & 50,53 & 5 & 252,6 \\
\hline CFL & $\begin{array}{c}25 \mathrm{~kg} / \\
\text { torba }\end{array}$ & 47,87 & 35 & 1675,4 \\
\hline CMC-LV & $\begin{array}{c}25 \mathrm{~kg} / \\
\text { torba }\end{array}$ & 38,30 & 44 & 1685,2 \\
\hline $\begin{array}{c}\text { Sitrik } \\
\text { Asit }\end{array}$ & $\begin{array}{c}25 \mathrm{~kg} / \\
\text { torba }\end{array}$ & 38,30 & 4 & 153,2 \\
\hline \multicolumn{4}{|c|}{ Toplam Kademe Maliyeti (\$) } & 5039,8 \\
\hline \multicolumn{4}{|c|}{ Birim Varil Maliyeti $(\$ / \mathbf{B b l})$} & 5,48 \\
\hline
\end{tabular}


22 inç kuyu çapı kademesinde kullanılan çamur katkı malzemeleri için 5039,88 \$'lık bir maliyet hesaplanmıştır. Hazırlanan yeni çamurun birim varil maliyeti ise 5,48 \$ olarak gerçekleşmiştir.

\section{3. $17^{1 / 2}$ inç Kuyu Çapı Kademesi}

Bu kademeye geçilmeden önce $18^{5 / 8}$ inç koruma borusu (Casing) indirilip çimentolanmıştır. Kademe boyunca çamur türü olarak 22 inç kuyu çap1 kademesinden kalan çamura ilaveten 2790 BBL hacminde hazırlanan lignosülfonat tip çamur kullanılmıştır. Reolojik özelliklerin korunabilmesi için sıvı kaybı azaltıcı ve viskozite artırıcı katkı malzemesi olarak bentonit, CMC-HV, CMC-LV ve PAC-LV kullanılmıştır. Deflokülant katkı malzemesi olarak CFL, pH kontrolü için kostik soda ve sertlik kontrolü için soda külü kullanılmıştır.

Bu kademede Flow-Line sıcaklığı en yüksek $61{ }^{\circ} \mathrm{C}$ değerine ulaşmıştır. Ayrıca casing ve bakım onarım süreleri dahil olacak şekilde ROP 25,2 metre/gün olarak hesaplanmıştır.

Kullanılan çamur katkı malzemelerinin ambalaj türü, tüketim miktarı ile birim varil ve toplam kademe maliyeti Çizelge 4'de verilmiştir.

Çizelge 4. $17^{1 / 2}$ inç kuyu çapı maliyet analizi

\begin{tabular}{|c|c|c|c|c|}
\hline Malzeme & Ambalaj & $\begin{array}{c}\text { Birim } \\
\text { Maliyet } \\
\mathbf{( \$ )}\end{array}$ & $\begin{array}{c}\text { Toplam } \\
\text { Kullanım } \\
\text { (Adet) }\end{array}$ & $\begin{array}{c}\text { Toplam } \\
\text { Maliyet } \\
\mathbf{( \$ )}\end{array}$ \\
\hline Bentonit & $\begin{array}{c}35 \mathrm{~kg} / \\
\text { torba }\end{array}$ & 5,65 & 68 & 384,2 \\
\hline Bentonit & $\begin{array}{c}1 \mathrm{ton} / \\
\text { BigBag }\end{array}$ & 161,70 & 2 & 323,4 \\
\hline $\begin{array}{c}\text { Soda } \\
\text { Külü }\end{array}$ & $\begin{array}{c}25 \mathrm{~kg} / \\
\text { Torba }\end{array}$ & 9,57 & 7 & 66,99 \\
\hline $\begin{array}{c}\text { Kostik } \\
\text { Soda }\end{array}$ & $\begin{array}{c}25 \mathrm{~kg} / \\
\text { torba }\end{array}$ & 23,94 & 36 & 861,84 \\
\hline CMC-HV & $\begin{array}{c}25 \mathrm{~kg} / \\
\text { torba }\end{array}$ & 50,53 & 4 & 202,12 \\
\hline CFL & $\begin{array}{c}25 \mathrm{~kg} / \\
\text { torba }\end{array}$ & 47,87 & 56 & 2680,72 \\
\hline CMC-LV & $\begin{array}{c}25 \mathrm{~kg} / \\
\text { torba }\end{array}$ & 38,30 & 36 & 1378,8 \\
\hline PAC-LV & $\begin{array}{c}25 \mathrm{~kg} / \\
\text { torba }\end{array}$ & 50,53 & 44 & 2223,32 \\
\hline \multicolumn{7}{|c|}{ Toplam Kademe Maliyeti (\$) } & $\mathbf{8 1 2 1 , 3 9}$ \\
\hline \multicolumn{7}{|c|}{ Birim Varil Maliyeti (\$/Bbl) } & $\mathbf{2 , 9 1}$ \\
\hline
\end{tabular}

$17^{1 / 2}$ inç kuyu çapı kademesinde kullanılan çamur katk1 malzemeleri için 8121,39 \$'lık bir maliyet gerçekleşmiştir. Hazırlanan yeni çamurun birim varil maliyeti ise 2,91 \$ olarak hesaplanmıştır.

\section{4. $12^{1 / 4}$ inç Kuyu Çapı Kademesi}

Bu kademeye geçilmeden önce $133^{/ 8}$ inç koruma borusu (Casing) indirilip çimentolanmıştır. Kademe boyunca çamur türü olarak $17^{1 / 2}$ inç kuyu çap1 kademesinden kalan çamura ilaveten 2500 BBL hacminde hazırlanan lignosülfonat tip çamur kullanılmıştır.

Bu kademede kuyu dibi hidrostatik basıncının kick akışkanından kaynaklı artışından dolayı barit ve kalsiyum karbonat ile çamur ağırlaştırılarak çamurun hidrostatik basıncı artırılmıştır.

Çamurun hazırlanmasında ve sirkülasyon esnasında reolojik özelliklerin korunabilmesi için Sıv1 kayb1 azaltıcı ve viskozite artırıcı katk1 malzemesi olarak bentonit, CMC-HV, PAC-LV ve XCD kullanılmıştır. Deflokülant malzeme olarak CFL, pH kontrolü için kostik soda, hidrostatik basıncı artırmak amaçlı çamur ağırlaştırıcı katkı malzemesi olarak barit ve $\mathrm{CaCO}_{3}$ kullanılmıştır.

Çizelge 5. $12^{1 / 4}$ inç kuyu çapı maliyet analizi

\begin{tabular}{|c|c|c|c|c|}
\hline Malzeme & Ambalaj & $\begin{array}{c}\text { Birim } \\
\text { Maliyet } \\
(\$)\end{array}$ & $\begin{array}{c}\text { Toplam } \\
\text { Kullanım } \\
\text { (Adet) }\end{array}$ & $\begin{array}{c}\text { Toplam } \\
\text { Maliyet } \\
(\$)\end{array}$ \\
\hline Bentonit & $\begin{array}{l}35 \mathrm{~kg} / \\
\text { Torba }\end{array}$ & 5,65 & 177 & 1000,5 \\
\hline Bentonit & $\begin{array}{c}1 \text { ton/ } \\
\text { BigBag }\end{array}$ & 161,70 & 2 & 323,4 \\
\hline Kostik Soda & $\begin{array}{l}25 \mathrm{~kg} / \\
\text { Torba }\end{array}$ & 23,94 & 44 & 1053,3 \\
\hline CMC-HV & $\begin{array}{c}25 \mathrm{~kg} / \\
\text { torba }\end{array}$ & 50,53 & 6 & 303,18 \\
\hline CFL & $\begin{array}{c}25 \mathrm{~kg} / \\
\text { torba }\end{array}$ & 47,87 & 83 & 3973,2 \\
\hline PAC-LV & $\begin{array}{c}25 \mathrm{~kg} / \\
\text { torba }\end{array}$ & 50,53 & 93 & 4699,29 \\
\hline $\mathrm{XCD}$ & $\begin{array}{l}25 \mathrm{~kg} \\
/ \text { torba }\end{array}$ & 143,62 & 3 & 430,8 \\
\hline Barit & $\begin{array}{l}1,5 \text { ton/ } \\
\text { BigBag }\end{array}$ & 287,24 & 39 & 11202,3 \\
\hline Barit & $\begin{array}{c}1 \text { ton/ } \\
\text { BigBag }\end{array}$ & 191,49 & 2 & 382,9 \\
\hline $\mathrm{CaCO}_{3}$ & $\begin{array}{c}1 \text { ton/ } \\
\text { BigBag }\end{array}$ & 85,10 & 5 & 425,5 \\
\hline \multicolumn{4}{|c|}{ Toplam Kademe Maliyeti (\$) } & 23794,19 \\
\hline \multicolumn{4}{|c|}{ Birim Varil Maliyeti (\$/Bbl) } & 9,517 \\
\hline
\end{tabular}


Flow-Line sicaklığı en yüksek $72,7{ }^{\circ} \mathrm{C}$ değerine ulaşmıştır. Ayrıca casing ve bakım onarım süreleri dahil olacak şekilde ROP 33,07 metre/gün olarak hesaplanmıştır.

Kullanılan çamur katkı malzemelerinin ambalaj türü, tüketim miktarı ile birim varil ve toplam kademe maliyeti Çizelge 5'de verilmiştir.

$12^{1 / 4}$ inç kuyu çapı kademesinde kullanılan çamur katk1 malzemeleri için 23794,19 \$'lık bir maliyet gerçekleşmiştir. Hazırlanan yeni çamurun birim varil maliyeti ise 9,517 \$ olarak hesaplanmıştır.

\section{5. $8^{1 / 2}$ inç Kuyu Çapı Kademesi}

$\mathrm{Bu}$ kademeye geçilmeden önce $9^{5 / 8}$ inç koruma borusu (Casing) indirilip çimentolanmıştır. 2542. metre'de sondaj tamamlanmıştır.

Kademe boyunca çamur türü olarak 2520 BBL hacminde hazırlanan polimer tip çamur kullanılmıştır. 2188. metre'den sonra ise sondaj çamuru olarak su kullanılmaya başlanılmıştır. Ayrıca periyodik aralıklar ile kuyu tabanındaki kırıntıları yüzeye almak ve overpull problemlerini gidermek amacıyla yüksek viskoziteli çamur (Hi-Vis) hazırlanmış ve tapa olarak kuyuya pompalar ile enjekte edilmiştir. Çamurun hazırlanmasında çamur katkı malzemeleri olarak pH kontrolü için kostik soda ve sitrik asit, sıvı kayb1 azaltıcı ve viskozite yapıc1 katkı malzemesi olarak XCD ve PAC-LV kullanılmıştır. Hidrostatik basıncı artırmak amaçlı çamur ağırlaştırıcı katkı malzemesi olarak $\mathrm{CaCO}_{3}$ kullanılmıştır. Kullanılan çamur katk1 malzemelerinin ambalaj türü, tüketim miktarı ile birim varil ve toplam kademe maliyeti Çizelge 6'da verilmiştir.

Flow-line sicaklığı en yüksek $73,7{ }^{\circ} \mathrm{C}$ değerine ulaşmıştır. Ayrıca casing ve bakım onarım süreleri dahil olacak şekilde ROP 33,23 metre/gün olarak hesaplanmıştır.

$8^{1 / 2}$ inç kuyu çapı kademesinde kullanılan çamur katk1 malzemeleri 16016,69 \$'lık bir maliyet gerçekleşmiştir. Hazırlanan yeni çamur için birim varil maliyeti 6,35 \$ olarak hesaplanmıştır.
Çizelge 6. $8^{1 / 2}$ inç kuyu çapı maliyet analizi

\begin{tabular}{|c|c|c|c|c|}
\hline Malzeme & Ambalaj & $\begin{array}{c}\text { Birim } \\
\text { Maliyet } \\
\text { (\$) }\end{array}$ & $\begin{array}{c}\text { Toplam } \\
\text { Kullanım } \\
\text { (Adet) }\end{array}$ & $\begin{array}{c}\text { Toplam } \\
\text { Maliyet } \\
\text { (\$) }\end{array}$ \\
\hline $\begin{array}{c}\text { Kostik } \\
\text { Soda }\end{array}$ & $\begin{array}{c}25 \mathrm{~kg} / \\
\text { Torba }\end{array}$ & 23,94 & 16 & 383,04 \\
\hline XCD & $\begin{array}{c}25 \mathrm{~kg} / \\
\text { Torba }\end{array}$ & 143,62 & 84 & 12064,08 \\
\hline PAC-LV & $\begin{array}{c}25 \mathrm{~kg} \\
\text { /torba }\end{array}$ & 50,53 & 49 & 2475,97 \\
\hline Sitrik Asit & $\begin{array}{c}25 \mathrm{~kg} / \\
\text { Torba }\end{array}$ & 38,30 & 13 & 497,9 \\
\hline $\mathrm{CaCO}_{3}$ & $\begin{array}{c}1 \text { ton/ } \\
\text { BigBag }\end{array}$ & 85,10 & 7 & 595,7 \\
\hline \multicolumn{5}{|c|}{ Toplam Kademe Maliyeti (\$) } \\
\hline \multicolumn{5}{|c|}{ Baril Maliyeti (\$/Bbl) } \\
\hline
\end{tabular}

\section{TOPLAM ÇAMUR MALİYETI}

Çamköy formasyonunda açılan 2542 metre derinliğe sahip sondaj kuyusunun bütün kademeleri boyunca toplam 9030 BBL çamur hazırlanmıştır.

Yapılan hesaplamalar sonucu tüm kademelerde kullanılan ve sondajın bitimine kadar kullanılan toplam çamur katkı malzemesi maliyeti 53464,43\$ olarak hesaplanmıştır (Çizelge 7).

Çamköy jeotermal sondaj kuyusunda kullanılan katkı malzemeleri maliyeti bakımından en yüksek tutarlar sırasıyla XCD, barit ve PAC-LV katkıları oluşturmuştur. En düşük maliyetli katkı malzemesi ise soda külü olarak belirlenmiştir.

Çizelge 7. Toplam çamur maliyeti

\begin{tabular}{|c|c|c|c|c|}
\hline $\begin{array}{l}\text { Kuyu } \\
\text { Çapı } \\
\text { (inç) }\end{array}$ & $\begin{array}{c}\text { Casing } \\
\text { Çapı } \\
\text { (inç) }\end{array}$ & Çamur Türü & $\begin{array}{c}\text { Çamur } \\
\text { Miktarı } \\
\text { (BBL) }\end{array}$ & $\begin{array}{c}\text { Maliyet } \\
(\$)\end{array}$ \\
\hline $26^{1 / 2}$ & 24 & Spud & 300 & 492,36 \\
\hline 22 & $18^{5 / 8}$ & Lignosülfonat & 920 & 5039,8 \\
\hline $17^{1 / 2}$ & $13^{3 / 8}$ & Lignosülfonat & 2790 & 8121,39 \\
\hline $12^{1 / 4}$ & $9^{5 / 8}$ & Lignosülfonat & 2500 & 23794,19 \\
\hline $8^{1 / 2}$ & $\begin{array}{c}7 \\
\text { (Liner) }\end{array}$ & Polimer & 2520 & 16016,69 \\
\hline \multicolumn{3}{|c|}{ TOPLAM } & 9030 & 53464.43 \\
\hline \multicolumn{4}{|c|}{ Birim Maliyet (\$/BBL) } & 5,921 \\
\hline
\end{tabular}


$\mathrm{Bu}$ hesaplamalar haricinde her bir kuyu çap1 kademesinin toplam maliyet üzerindeki yüzde (\%) maliyet değeri de Şekil 5 'te verilmiştir.

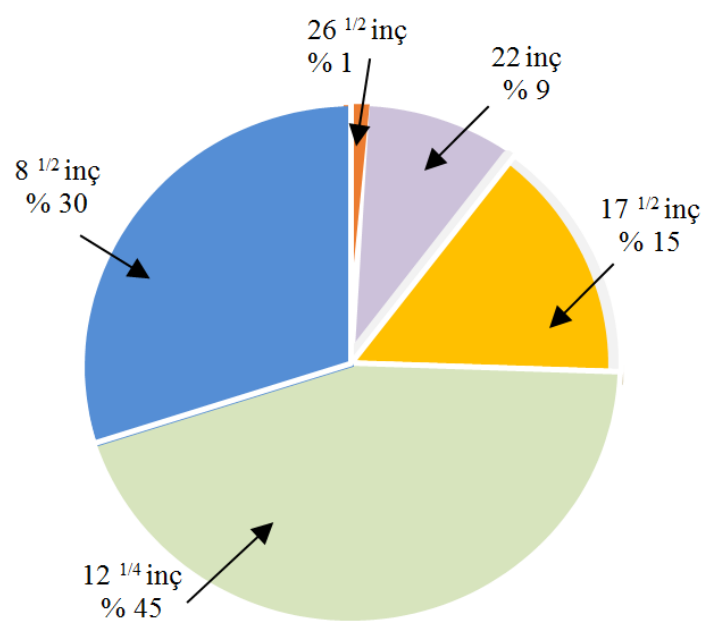

Şekil 5. Kuyu çapı kademe maliyetlerinin toplam çamur maliyetindeki yüzdesi

Şekil 5 ile görüleceği üzere en yüksek çamur katk1 maliyeti $12^{1 / 4}$ inç kademe ilerlemesinde gerçekleşmiştir. $\mathrm{Bu}$ çaptaki ilerleme esnasında kullanılan çamur katkı malzemelerinin maliyeti toplam çamur katkı malzemeleri maliyetine oranı $\% 45$ olarak belirlenmiştir.

$12^{1 / 4}$ inç çap kademesi ilerleyişinde kick akışkanından kaynaklı karşılaşılan kuyu dibi hidrostatik basıncının artışından dolayı barit ve $\mathrm{CaCO}_{3}$ ile çamur ağırlaştırılması gerçekleştirilmiştir. Bu durumda çamur maliyeti de yüksek olmuştur.

En düşük çamur katkı maliyeti ise tüm sondaj çamur katk1 malzemesi maliyeti oranına göre $\% 1^{\prime}$ lik bir maliyet tutan $26^{1 / 2}$ inç kademesinde gerçekleşmiştir.

\section{SONUÇLAR}

Çanakkale İli Tuzla Bölgesi Çamköy formasyonunda $2542 \mathrm{~m}$ derinliğinde olan ve $26^{1 / 2}$, 22, $17^{1 / 2}, 12^{1 / 4}, 8^{1 / 2}$ kuyu çapı kademelerinde yapılan sondajlarda spud, lignosülfonat ve polimer çamurları kullanılmıştır. Bu çamurlar hazırlanırken çamur katkı malzemesi olarak bentonit, CMC-HV, CMC-LV, soda külü, sitrik asit, kostik soda, CFL, PAC-LV, XCD, barit ve $\mathrm{CaCO}_{3}$ kullanılmıştır.

Yapılan hesaplamalar sonucu tüm kademelerde kullanılan ve sondajın bitimine kadar kullanılan toplam çamur katkı malzemesi maliyeti 53464,43 \$ olarak hesaplanmıştır. Çamur katk1 malzemeleri maliyeti bakımından en yüksek maliyeti sirasıyla XCD, Barit ve PAC-LV oluşturmuştur. En düşük maliyetli katkı malzemesi ise Soda külü olarak görülmektedir.

En yüksek çamur katkı maliyeti $12^{1 / 4}$ inç kademe ilerlemesinde gerçekleşmiştir. Bu çaptaki ilerleme esnasında kullanılan çamur katkı malzemesinin maliyetinin toplam çamur katkı malzemelerinin maliyetine oranı $\% 45$ olarak belirlenmiştir.

Yapılan çalışmanın sonucunda toplamda 9030 BBL sondaj çamuru kullanılmış ve bunun toplam maliyeti 53.464,43 \$ olarak hesaplanmıştır. Birim maliyet ise 5,921 \$/BBL'dir.

Elde edilen maliyet verilerinin Çamköy formasyonunda planlanan jeotermal kaynak sondajları için toplam çamur maliyeti, birim varil maliyeti ve birim metre maliyetinin hesaplanmasında yol göstermesi bakımından büyük bir önem arz etmektedir.

\section{KAYNAKLAR}

1. Tekin, S. 2011. Jeotermal Sondaj1, Maliyet Faktörleri ve Kontratları, Jeofizik Bülteni, Eylül-Aralık, 21-25, Ankara.

2. Fabbri, F., Vidali, M. 1970. Drilling Mud in Geothermal Wells, Geothermics, Special Issue 2,735-741.

3. Çandar, Ö., 2014. Çanakkale-Tuzla Yöresi Jeotermal Sularının Kabuklaşma ve Korozyon Özelliklerinin İncelenmesi. Dokuz Eylül Üniversitesi Fen Bilimleri Enstitüsü Yüksek Lisans Tezi, İzmir.

4. Duru, M., Pehlivan Ş., Okay A.İ., Şentürk Y., Kar, H., 2009. Biga Yarımadasının Tersiyer Öncesi Jeolojisi. Biga Yarımadasının Genel ve Ekonomik Jeolojisi, MTA Rapor No:11101, Ankara. 
5. Çam, D., Bülbül, E., Kılınç, O., Şan, Ö., 2013. Maden Tetkik ve Arama Genel Müdürlüğü, Ekonomi Bültenleri, 79, Ankara.

6. American Petroleum Institute (API), 2010, Specification for Drilling FluidsSpecifications and Testing, USA.

7. Türk Standard 1 13500, 2006. Petrol ve Doğalgaz Sanayii-Sondaj Çamuru MaddeleriÖzellikleri ve Deneyler, Ankara, Türkiye.

8. TPAO, 2004. Araştırma Merkezi Sondaj Teknolojisi Müdürlüğü, Ankara.

9. TPAO, 2007. Sondaj Akışkanları Teknolojisi, Türkiye Petrolleri Anonim Ortaklığı, Araştırma Merkezi Daire Başkanlığı, Ankara.

10. Erdoğan, Y. ve Kök, O.E., 2017. Çamköy Formasyonundaki Jeotermal Sondaj Çamurunun Reolojik ve Kimyasal Özelliklerinin İncelenmesi, Türkiye 25. Uluslararas1 Madencilik Kongresi, Bildiriler Kitab1, Cilt 1, 763-775, Antalya. 